\title{
Observância da lei de acesso à informação pelas autarquias federais do Brasil
}

Joyce Mariella Medeiros Cavalcanti

Aluna do Programa de Pós-Graduação em Administração pela UFRN, na área de concentração em Gestão Organizacional

Larissa Mayara da Silva Damasceno,

Aluna do Programa de Pós-Graduação em Administração pela UFRN, na área de concentração em Gestão Organizacional

Manoel Veras de Souza Neto

Prof. Dsc. Associado da UFRN na área de Administração, com ênfase em Tecnologia da Informação

Este estudo analisa a conformidade dos sítios eletrônicos das autarquias federais, em relação à Lei de Acesso a Informação. A pesquisa é exploratória e descritiva com abordagem quantitativa, cujo instrumento é uma Listagem de Verificação com dezenove itens. Os resultados demonstraram que, em média, $66 \%$ da amostra cumpriram com os itens e, em pontos específicos, como classificação das informações sigilosas, cópias de contratos, disponibilização de relatórios em formatos de planilha/texto e estruturação da informação, houve descumprimento acima de $90 \%$.

Palavras-chave: Governo eletrônico; Open government; Lei de acesso à informação; Autarquias federais.

\section{Compliance with the law of access to information by federal authorities of}

Brazil

This study examines the compliance of websites of federal autarchies in relation to the determinations of Access to Information Act. The research is exploratory and descriptive quantitative approach, which is an instrument Listing 
Verification with nineteen items. The results showed that, on average, $66 \%$ of the sample met the items, and specific points, such as classification of sensitive information, copies of contracts, provision of reports in spreadsheet formats / text and structuring information noncompliance was above $90 \%$.

Key-words: Electronic government; Open government; The access to information law; Federal autarchies.

Recebido em 11.03.2013Aceito em 16.10.2013

\section{Introdução}

No contexto atual, a informação passa a ser um dos fatores essenciais para que as empresas sejam competitivas e, para tal, é necessário que elas adotem práticas que permitam incrementar seu desempenho para continuar no mercado. Essa necessidade por um melhor desempenho alcançou o setor público, visto que ele também precisa responder às novas demandas da sociedade.

O alicerce para esse novo cenário econômico e social é construído pelas Tecnologias de Informação e Comunicação (TICs) - em especial a Internet - cujos impactos sociais, econômicos e financeiros devem ser monitorados, com o objetivo de elaborar políticas eficazes para as instituições públicas (ARAÚJO; LAIA, 2004; BARBOSA, 2008). As TICs também têm como objetivo estabelecer uma comunicação e interação entre o governo e a população além do incentivo à democracia eletrônica.

O uso dessas Tecnologias da Informação para a execução dos processos de governo é denominada Governo Eletrônico, que, de acordo com Lemos (2004), objetiva regenerar o espaço público, aperfeiçoar os serviços prestados à população e estimular a interação e discussão dos problemas locais. Em função dessa busca pela melhoria da eficiência na prestação desses serviços públicos, pode-se inferir que ele -o Governo Eletrônico- é elemento da Governança Eletrônica.

Ainda sobre o estímulo para a interação e discussão da sociedade, tem-se adotado no país as práticas de Governo Aberto (Open Government Partnership (OGP)), iniciativa internacional que visa a difundir e incentivar globalmente práticas relacionadas à transparência dos governos, acesso à informação pública e participação social (ACESSO À INFORMAÇÃO, 2012a).

Um destaque dentre as práticas de Governo Aberto foi a aprovação da Lei de Acesso à Informação Pública (Lei Federal no 12.527, de 2011) (BRASIL, 2011), publicada em 18 de novembro de 2011. Essa Lei se propõe a regulamentar o acesso à informação pública no Brasil, com a finalidade de incrementar os meios para que a população possa fiscalizar os instrumentos de controle da gestão pública. Isso constitui um controle social que, para Gruman (2012), é um complemento indispensável ao 
controle institucional realizado pelos órgãos que fiscalizam os recursos públicos.

A Lei de Acesso à Informação Pública, além de propor meios mais claros para o direito de acesso à informação, também representa uma mudança de paradigma em matéria de transparência pública (ACESSO À INFORMAÇÃO, 2012b). Assim, quando proporcionado ao cidadão o direito de solicitar acesso às informações públicas, há possibilidade de acompanhar a gestão e o andamento de políticas públicas de forma mais eficiente e, sobretudo, participativa e inclusiva. Desse modo, o sigilo que era regra na maioria das operações, em especial durante o período da ditadura militar - passa a ser exceção.

Para garantir que a referida Lei está sendo cumprida e, portanto, se a sociedade tem tido acesso às informações públicas, o presente artigo tem como objetivo analisar a conformidade dos sítios eletrônicos das autarquias federais com relação às determinações da Lei de Acesso a Informação (LAI) e contribuir para a literatura sobre o tema, que, por ser recente, ainda há uma incipiente quantidade de trabalhos científicos.

A estrutura das sessões seguintes é composta por um levantamento bibliográfico sobre as temáticas de governo eletrônico, open government e a Lei de Acesso à Informação; seguida por Metodologia, Resultados e Conclusões.

\section{Governo eletrônico e open government}

Com as reformas na Administração Pública, a revolução digital introduzida pela Internet e a consolidação da democracia no Brasil, os cidadãos passaram a possuir instrumentos para fiscalizar a gestão pública, conduzindo a um aumento na procura por informações governamentais (MELLO; SLOMSKI, 2010).

Diante desse contexto, a necessidade informacional e a prestação de serviços governamentais pela Internet ensejaram o desenvolvimento do Governo Eletrônico (e-gov). Para Medeiros e Guimarães (2006), o e-gov pode ser compreendido como a prestação de informações e a disponibilização de serviços governamentais por meio da Internet pela Administração Pública.

$\mathrm{Na}$ literatura sobre este tema, observa-se que existem diversos conceitos de e-gov que ultrapassam a ideia da utilização da Internet pela gestão pública (DINIZ et al., 2009). Esse conceito abrange as diversas formas de interação entre governo e sociedade sob a égide da transparência governamental (JAEGER; THOMPSON, 2004; PINHO, 2008; ANGÉLICO, 2011; LAIA et al., 2011). Tal relacionamento entre governo e cidadãos é conhecido na literatura por G2C ou government-to-citizen (EVANS; YEN, 2006).

Na visão de Welch, Hinnant e Moon (2005), o relacionamento apontado por Evans e Yen (2006) é importante devido à assimetria de informação existente entre governo e cidadãos. Quando o governo se dispõe a aumentar a distribuição da informação, a capacidade dos 
cidadãos em observar e compreender as operações do governo aumenta, podendo melhorar a "confiança fiduciária" dos cidadãos com o governo (WELCH et al., 2005).

Desse modo, alinhar os conceitos de e-gov com a finalidade de minimizar a assimetria informacional entre governo e sociedade podem ser alcançados. Dentre os benefícios disso, Diniz et al. (2009) destacam: desempenho, eficiência, eficácia, transparência, mecanismos de controle, qualidade do gasto público e accountability.

O alcance desses objetivos tem sido almejado a nível internacional, pois a implementação de ações concretas de combate à corrupção, mobilização de novas Tecnologias de Informação e Comunicação, promoção da transparência governamental e incentivo à participação social na gestão governamental tem ganhado espaço na agenda pública em diversos países ao redor do Mundo.

Um deles é o The Open Government Partnership (OGP), um movimento mundial que abarca esses temas. Lançado oficialmente em 20 de Setembro de 2011, seu objetivo é de assegurar compromissos concretos por parte dos governos para fortalecer a governança e torná-los melhores. O OGP conta com 47 países que assumiram publicamente um alto nível de declaração de Governo Aberto, comprometendo-se em entregar um plano de ação para consulta pública e reportar sobre o andamento de seu progresso (OGP, 2013).

Em uma reflexão sobre o conceito de governo aberto, Meijer, Curtin e Hillebrandt (2012) discorrem que não se trata apenas da abertura em termos informativos, mas, também, em termos interativos. De acordo com os autores, os cidadãos precisam de informação para ver o que está acontecendo dentro do governo e de voz para participar e expor suas opiniões. Sendo assim, para os autores, voz e visão se unem na ideia de debate informado.

A defesa pelo amplo debate e pela participação social são temas adotados pelo OGP, do qual o Brasil faz parte. No biênio de 2011-2012, o Comitê Diretor Internacional da iniciativa contou com a copresidência do Brasil e dos Estados Unidos da América (ACESSO À INFORMAÇÃO, 2012a). Essa participação propiciou ao governo brasileiro a incorporação da ideia de que a informação é um bem público e, por isso, deve estar disponível e inteligível para a sociedade.

Para colocar essa filosofia em prática, Araújo e Laia (2004) comentam que o e-gov representa uma oportunidade ímpar de relacionar as estratégias de reforma administrativa com a possibilidade de fornecimento de informações aos cidadãos, promovendo alterações em sua cultura e estrutura.

No Brasil, o e-gov surgiu através do Decreto Presidencial de 3 de Abril de 2000, que, através de posteriores Programas de Governo Eletrônico, promoveram a democracia eletrônica no país. Para Rezende e Frey (2005), essa mobilização da informação trás benefícios para performance da Administração Pública, tornando-a mais ágil e eficiente. 
Outras ações mais recentes do governo que buscaram, de forma efetiva, estabelecer a relação G2C e aproximar o cidadão na tomada de decisão dos gestores públicos foi realizada por meio da disponibilização de dados abertos hospedados no sítio eletrônico do dados.gov e por meio da Lei de Acesso à Informação Pública, transferindo informação e conhecimento aos cidadãos.

\section{Lei de acesso à informação pública (Lei Federal no 12.527, de 2011)}

Aprovada em 18 de Novembro de 2011 e em vigor desde 16 de Maio de 2012, a Lei Federal no 12.527, de 2011 (BRASIL, 2011), conhecida como Lei de Acesso à Informação (LAI), consolidou a participação democrática dos cidadãos na gestão pública, oferecendo-Ihes mecanismos de combate à corrupção, exigência pela accountability governamental e incentivo à transparência pública. Além desses benefícios, Gruman (2012) destaca, também, o estabelecimento de inovações na forma de gerir a coisa pública em parceria com a população.

A Lei Federal no 12.527, de 2011 (BRASIL, 2011), representa uma mudança paradigmática na gestão governamental, pois determina que o amplo acesso à informação é a regra e o sigilo, a exceção (CONTROLADORIA GERAL DA UNIÃO, 2011), promovendo a cultura da transparência na Administração Pública em detrimento da cultura do segredo. Esse direito independe de solicitação, é reconhecido como direito humano fundamental pelo art. 190 da Declaração de Direitos Humanos e também garantido pela Constituição Federal Brasileira, no inciso XXXIII, do art. $5^{\circ}$ (CONTROLADORIA GERAL DA UNIÃO, 2009).

O direito ao acesso à informação assegura que qualquer cidadão que deseje receber informações públicas não classificadas como sigilosas possa obtê-las nos sítios eletrônicos oficiais dos órgãos e entidades públicas, conforme determinam os art. $1^{\circ}$, art. $2^{\circ}$, art. $8^{\circ} \S 20$, art. $23 \mathrm{e}$ art. 24 da Lei Federal no 12.527, de 2011 (BRASIL, 2011).

Dentre as informações divulgadas aos cidadãos e disponibilizadas na internet, a Lei Federal no 12.527, de 2011 (BRASIL, 2011) determina que deve ser informado, no mínimo, o registro das despesas; procedimentos licitatórios e contratos celebrados; conteúdos para acompanhamento de programas, projetos e obras de órgãos e entidades; respostas a perguntas mais frequentes da sociedade; declaração de transferências ou repasses de recursos financeiros; e dados para contato e descrição das competências e da estrutura organizacional.

Para Angélico (2011), a Lei só atingirá os efeitos desejados se houver o engajamento efetivo da população. O autor continua a destacar que outros enclaves, somados àquele desafio, surgem quando se considera o federalismo brasileiro, as dificuldades dos níveis subnacionais, as desigualdades técnicas e financeiras dos entes governamentais, beneficiamento de grupos privados e reforço ao já desigual acesso às novas tecnologias. 
Cabe ressaltar, no entanto, que disponibilizar a informação em ambientes eletrônicos não confere ao usuário a compreensão e, sobretudo, a capacidade de fazer conclusões acerca de seu conteúdo. Michener (2011) e Angélico (2011) lembram que, para estabelecer uma transparência clara da informação de modo que seja possível fazer inferências, os governos terão que aprender a registrar, catalogar e organizar as informações, além de disponibilizá-las de maneira mais adequada na Internet.

A troca de experiências internacionais que tratam sobre leis de acesso à informação pode ser uma forma de contornar tais problemas.

\section{Metodologia}

Esta pesquisa caracteriza-se como descritiva e exploratória, com abordagem quantitativa. A coleta de dados foi realizada através de um levantamento de critérios preestabelecidos com base nas determinações instituídas pela LAI. Para compor a amostra, foram selecionadas aleatoriamente 30 das 156 autarquias federais, listadas no sítio eletrônico da Advocacia Geral da União (AGU).

Dentre os critérios pré-estabelecidos para análise, foram destacados pontos exigidos pela referente Lei que podem ser verificados nos sítios eletrônicos oficiais dos entes públicos. Nesta pesquisa, foram analisados os sítios eletrônicos oficiais das autarquias federais, porque se espera que elas sigam mais rigorosamente as determinações da Lei de Acesso à Informação, visto que são subordinadas às fiscalizações da Controladoria Geral da União (CGU).

Desse modo, foi feita uma listagem de verificação com 19 perguntas relacionadas aos artigos $6^{\circ}$ ao $10^{\circ}$ da LAI, que dispõem sobre as garantias ao direito de acesso, regras sobre a divulgação de rotina ou proativa de informações e pedidos de acesso à informação.

O Quadro 1 apresenta a listagem de verificação utilizada nesta pesquisa.

Quadro 1 - Lista de verificação da Lei de Acesso à Informação

\begin{tabular}{l} 
PERGUNTAS \\
\hline 1) Está disponível a apresentação de metas e indicadores? \\
2) Estão disponíveis os resultados de inspeções e auditorias? \\
3) As prestações e tomadas de contas realizadas pelos órgãos de controle interno e externo estão divulgadas? \\
4) As prestações de contas dos exercícios anteriores estão disponíveis? \\
5) Está disponível o registro das competências e estrutura organizacional, endereços e telefones das respectivas \\
unidades? \\
6) Foram registrado quaisquer repasses ou transferências de recursos financeiros? \\
7) Estão disponíveis os registros das despesas? \\
8) Existem informações concernentes a procedimentos licitatórios, inclusive os respectivos editais bem como os \\
contratos celebrados? \\
9) Estão disponíveis os dados gerais para o acompanhamento de programas, ações, projetos e obras de órgãos e \\
entidades? \\
10) Existe alguma informação relativa a respostas a perguntas mais frequentes da sociedade? \\
11) O site contém o ícone de acesso à informação em fácil visualização? \\
12) O site possibilita o acesso automatizado por sistemas externos estruturados e legíveis por máquina? \\
13) São garantidas a autenticidade e a integridade das informações disponíveis para acesso? \\
14) Estão disponíveis o endereço e telefone do local de atendimento ao público?
\end{tabular}




\footnotetext{
15) Foi viabilizada alternativa de encaminhamento de pedidos de acesso por meio de seus sítios oficiais na internet?

16) Foram expostas quais são as informações sigilosas e da informação pessoal, observada a sua autenticidade, integridade e eventual restrição de acesso?

17) São disponibilizadas as cópias dos contratos administrativos?

18) O site possibilita a gravação de relatórios em diversos formatos eletrônicos, inclusive abertos e não proprietários, tais como planilhas e texto, de modo a facilitar a análise das informações?

19) São divulgados, em detalhes, os formatos utilizados para estruturação da informação?
}

Fonte: Produzido pelas autoras, com base na Lei Federal no 12.527, de 2011 (BRASIL, 2011).

Essa listagem de verificação, conforme pode ser visualizada no Quadro 1, é composta por 19 perguntas de resposta dicotômica, atribuindo o valor de 1 para sim e de 0 para não, com o objetivo de verificar se a autarquia atende aos critérios questionados e previstos em Lei. As perguntas não possuem pesos, o que faz a pontuação máxima ser de 19 pontos. Ressalta-se que essa verificação foi realizada no dia 19 de Janeiro de 2013, nos respectivos portais eletrônicos destacados na sessão seguinte, havendo a possibilidade de que, no futuro, os elementos da amostra possam cumprir com alguns itens que não foram contemplados neste estudo.

\section{Discussão de resultados}

As autarquias que compuseram a amostra deste estudo estão vinculadas a diferentes Ministérios. Dentre elas, $60 \%$ são Universidades e Institutos Federais de ensino vinculados ao Ministério da Educação, aproximadamente $6,5 \%$ da amostra corresponde ao Ministério da Saúde e outros 6,5\% ao Ministério de Minas e Energia. Os 27\% restantes correspondem, na ordem de um pouco mais de $3 \%$ cada, aos Ministérios da Cultura, Meio Ambiente, Previdência Social, Transportes, Justiça, Relações Exteriores, Turismo e Integração Nacional.

De posse das autarquias que compuseram a amostra e com base na listagem de verificação proposta no Quadro 1 , o percentual de cumprimento da Lei de Acesso à Informação e a pontuação média obtida estão descritas no Gráfico 1 e na Tabela 1.

Gráfico 1 - Percentual de observância das autarquias que obedeceram aos critérios da Lei de Acesso à Informação, estabelecidos pela Listagem de Verificação

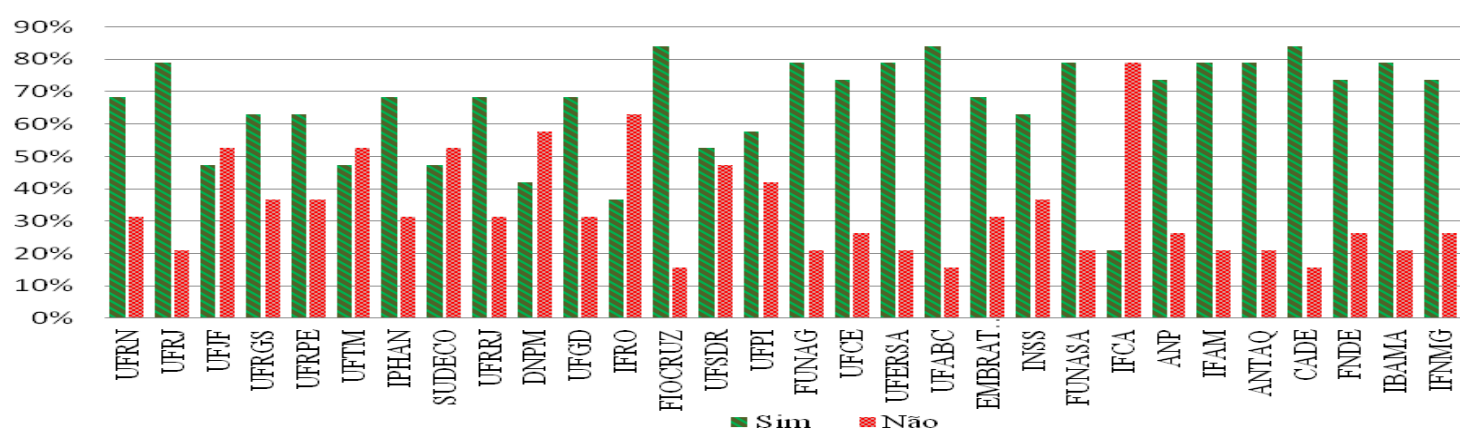

Fonte: Dados da pesquisa. 
No Gráfico 1, percebe-se maior quantidade de barras verdes acima de 50\%, apontando que a amostra seguiu, de modo geral, as determinações da Lei. Essa verificação inicial é ratificada por uma maior variação das barras com diagonais de cor verde, referente ao cumprimento dos critérios da LAI. Por outro lado, observa-se, também, um maior percentual de descumprimento, representado pelas colunas quadriculadas de cor vermelha, nas autarquias federais de educação em relação às demais autarquias vinculadas a outros Ministérios que apresentaram maior conformidade.

A análise da estatística descritiva da amostra presente na Tabela 1 , apresenta outras informações interessantes sobre o comportamento da amostra.

Tabela 1 - Desempenho geral da amostra, de acordo com a Listagem de Verificação

\begin{tabular}{cccc}
\hline & MÉDIA & MINIMO & MÁXIMO \\
\hline \hline SIM & $66 \%$ & $21 \%$ & $84 \%$ \\
NÃO & $34 \%$ & $16 \%$ & $79 \%$ \\
\hline
\end{tabular}

Fonte: Dados da pesquisa.

De acordo com a Tabela 1, em média, 66\% das autarquias federais estão obedecendo aos questionamentos realizados na listagem de verificação, enquanto $34 \%$, ou seja, menos da metade da amostra, não seguiu alguns dos itens expostos no Quadro 1. Além disso, a pontuação máxima de observância obtida foi de $84 \%$, que foi alcançada por duas autarquias, ao passo que apenas uma não seguiu em $79 \%$ os questionamentos desta pesquisa.

Vale ressaltar que alguns dos itens verificados possuem teor mais específico da LAI enquanto outros foram contemplados em legislações anteriores a referida Lei, fazendo-se necessário verificar cada questionamento isoladamente. Nesse sentido, apesar de ser constatado que, em média, as autarquias pesquisadas seguiram as determinações da LAI, ao analisar a frequência de cumprimento de cada uma das dezenove perguntas em relação ao total da amostra, percebeu-se particulares nessa distribuição conforme pode ser observado na Tabela 2.

Tabela 2 - Distribuição percentual da amostra por pergunta contida na Listagem de Verificação

\begin{tabular}{cccccccccccccccccccc}
\hline Pergunta & $\mathbf{1}$ & $\mathbf{2}$ & $\mathbf{3}$ & $\mathbf{4}$ & $\mathbf{5}$ & $\mathbf{6}$ & $\mathbf{7}$ & $\mathbf{8}$ & $\mathbf{9}$ & $\mathbf{1 0}$ & $\mathbf{1 1}$ & $\mathbf{1 2}$ & $\mathbf{1 3}$ & $\mathbf{1 4}$ & $\mathbf{1 5}$ & $\mathbf{1 6}$ & $\mathbf{1 7}$ & $\mathbf{1 8}$ & $\mathbf{1 9}$ \\
\hline \hline Sim (\%) & 80 & 83 & 63 & 63 & 90 & 80 & 87 & 90 & 77 & 80 & 93 & 90 & 100 & 83 & 80 & 3 & 7 & 7 & 7 \\
Não (\%) & 20 & 17 & 37 & 37 & 10 & 20 & 13 & 10 & 23 & 20 & 7 & 10 & 0 & 17 & 20 & 97 & 93 & 93 & 93 \\
\hline
\end{tabular}

Fonte: Dados da pesquisa.

As perguntas 1 a 15 questionaram aspectos que já eram exigidos em legislações anteriores a LAI ou que já eram divulgadas por outras razões, tais como a transparência na gestão pública e, provavelmente, por isso, exibiram maior observância por parte das autarquias federais pesquisadas, sendo essas perguntas analisadas primeiramente. 
No questionamento $1,80 \%$ da amostra apresentaram suas metas e indicadores, porém os documentos cuja informação foi divulgada variaram. Algumas autarquias disponibilizaram as metas e indicadores no Relatório de Gestão, enquanto outras no Plano Plurianual ou na Lei de Diretrizes Orçamentárias ou, ainda, na Lei Orçamentária Anual e algumas outras em anuários estatísticos.

As perguntas 2, 3 e 4 são referentes à auditoria e prestação de contas. Essas obrigações já eram previstas na Lei Complementar 101, de 4 de Maio de 2000. Apesar de estarem vinculadas, pois toda prestação de contas das autarquias públicas federais devem ser submetida à auditoria interna e externa, nem todas disponibilizaram essas informações conjuntamente. A pergunta 2, por exemplo, apresentou $83 \%$ de cumprimento, enquanto que os itens 3 e 4 exibiram os mesmos percentuais, ou seja, $63 \%$ das autarquias que disponibilizaram a prestação de contas através de relatórios contábeis ou pelo Relatório de Gestão também apresentaram os mesmos demonstrativos relativos à exercícios anteriores.

A divulgação de dados institucionais detalhados foram contemplados no item 5. Do total, $90 \%$ da amostra, o que equivale a 27 autarquias federais, divulgaram concomitantemente seus endereços; estrutura organizacional; competências; e telefones. Desse modo, se alguma autarquia não atendeu a pelo menos um desses quesitos, considerou-se o descumprimento da mesma.

As perguntas 6, 7, 8 e 12 apresentaram dois aspectos em comum: cumprimento acima de $80 \%$ e encaminhamento ao sítio eletrônico do Portal da Transparência Pública pela maioria das autarquias, sendo permitido direcionar os usuários a outros sistemas (ou sítios eletrônicos oficiais) que possuam as informações exigidas pela LAI, sem prejuízo de sua observância, representado pelo item 12 . Esses questionamentos dispõem sobre a obrigação de divulgar repasses ou transferências de recursos financeiros, o registro das despesas, informações sobre procedimentos licitatórios que estão previstos na Lei de Licitações (Lei Federal no 8.666, de 21 de Junho de 1993), na Lei do Pregão Eletrônico (Lei Federal no 10.520, de 17 de Julho de 2002) e na Lei da Transparência Fiscal (Lei Complementar no 101, de 4 de Maio de 2000 e pela Lei Complementar no 131, de 25 de Maio de 2009).

O Relatório de Gestão também foi objeto de análise para verificação de cumprimento da pergunta 9 e, por esse motivo, apresentou percentuais bastante próximos a pergunta 1 . Neste item, $77 \%$ das autarquias evidenciaram dados gerais para acompanhamento de programas, ações, projetos e obras em seus sítios eletrônicos. Esses dados podem ser compreendidos como uma forma de prestar contas e comparar o que foi previsto versus executado para que a sociedade possa avaliar a eficiência e eficácia da Administração Pública Federal.

Com relação à pergunta 10 , cerca de $80 \%$ da amostra apresentaram uma série de perguntas e respostas sobre dúvidas gerais da sociedade relativas à autarquia, mas apenas uma apresentou perguntas e respostas 
sobre a Lei de Acesso à Informação. Como a Lei é bastante abrangente, não está claro sobre quais matérias devem versar essas perguntas, apenas especifica que deve constar no site respostas a questionamentos gerais da sociedade, portanto, para fins de computação de cumprimento, foi considerado o atendimento a esse quesito.

Já no questionamento 11 , houve cumprimento de $93 \%$ da amostra em exibir, na página inicial de seus sítios eletrônicos, o ícone da LAI. No item 13, foi pressuposto que todos os sítios eletrônicos oficiais das autarquias federais analisadas disponibilizaram informações autênticas e íntegras, ou seja, houve aproveitamento total deste item.

Por fim, as perguntas 14 e 15 estão atreladas, pois a primeira refere-se à disponibilização de endereço e telefone do serviço de informação ao cidadão e a segunda sobre a possibilidade de envio de solicitação de informações por meio físico. Desse modo, em relação ao item 14, cerca de $83 \%$ da amostra cumpriram com esta determinação, enquanto $80 \%$ apresentaram a possibilidade de formulários impressos para solicitação de informações.

Analisando os questionamentos mais específicos da LAI que foram inseridos na listagem de verificação proposta nesta pesquisa, as perguntas 16 a 19 apresentaram descumprimentos acima de 90\% em cada uma delas, no dia em que foram investigados seus portais eletrônicos e com base na metodologia adotada nesta pesquisa.

Para fins desta pesquisa, considera-se o cerne desta Lei a pergunta 15, porque trata da classificação das informações sigilosas e de informação pessoal, marcando a transição da cultura do segredo para a cultura da transparência na Administração Pública. Neste item, apenas uma autarquia apresentou, ainda que em linhas gerais, quais eram as informações classificadas como secretas, ultrassecretas e reservadas, havendo descumprimento em 90\%. Apesar de representativo, o descumprimento desse item pode ser atribuído ao prazo de dois anos, a partir da data de vigência da LAI, para as autarquias classificarem as informações como tal. Portanto, até a presente data, as autarquias federais estão dentro do prazo para o levantamento do rol de informações que serão classificadas como sigilosas para, em seguida, esclarecê-las à sociedade.

A pergunta 17 , referente à disponibilização das cópias dos contratos administrativos, obteve um percentual de $93 \%$ de respostas 'não', enquanto apenas duas autarquias, ou seja, 7\% da amostra, disponibilizaram cópias de seus contratos em formatos legíveis por máquinas. No questionamento 18, houve descumprimento de $93 \%$ da amostra em não fornecer aos usuários relatórios em diversos formatos eletrônicos, tais como planilhas e texto. Neste item, apenas uma autarquia disponibilizou esses relatórios nos dois formatos. Quando disponibilizado apenas um dos dois, considerou-se o não cumprimento do mesmo.

No último item específico LAI constante na Listagem de Verificação, a pergunta 19 versa sobre a estruturação da informação, entendida, para 
fins desta pesquisa, como um facilitador da navegação do sítio eletrônico pelos usuários. Nesta pesquisa, entende-se como uma forma de seguir esse item a disponibilização de um organograma, manual ou folder sobre como encontrar as principais informações sobre LAI no sítio eletrônico da autarquia investigada. Neste item, 93\% da amostra descumpriram com esta recomendação.

Diante o exposto, verificou-se que as 30 autarquias analisadas seguiram, em média, as determinações da Lei de Acesso a Informação que estavam presentes nesta Listagem de Verificação e atenderam à metodologia proposta. No entanto, alguns pontos merecem ser destacados. Por exemplo, analisando alguns quesitos mais específicos da Lei, verificou-se descumprimento em proporções bastante expressivas, isto é, acima de $90 \%$. Pressupõe-se que essas determinações mais específicas requerem um empenho maior dessas autarquias em produzir essas informações que não estavam prontas antes da referida Lei, pois, além de uma questão legal, ela implica em mudanças paradigmáticas nas Organizações Públicas e na forma de geri-la, sendo o Open Government um movimento internacional bastante recente sobre o assunto e do qual o Brasil é signatário.

\section{Conclusões}

O presente estudo teve como objetivo analisar a conformidade dos sítios eletrônicos das autarquias federais com relação às determinações da Lei de Acesso a Informação (LAI), por meio de uma Listagem de Verificação, composta por 19 questionamentos baseados na Lei que foram verificados em 30 autarquias federais, selecionadas aleatoriamente, no sítio eletrônico da Advocacia Geral da União.

Os resultados encontrados demonstraram que a pontuação máxima obtida pela amostra foi de $84 \%$ e que, em média, $66 \%$ das autarquias federais seguiram as determinações da LAI. Nesse sentido, verifica-se que mais da metade da amostra analisada divulgou suas informações para a sociedade de forma transparente, mas que ainda há autarquias que não cumprem com todas as determinações, dentre elas destacou-se as vinculadas ao Ministério da Educação.

Ao analisar as perguntas da Listagem de Verificação isoladamente, no entanto, verifica-se um comportamento concentrado em alguns itens. Por exemplo, itens que questionavam os registros das despesas, divulgação de repasses ou transferências, estabelecimento de metas e indicadores, ações e programas, inspeções de auditoria, prestação de contas, procedimentos licitatórios e de contratos, foram, em média, atendidos em mais de $60 \%$. O cumprimento desses itens obedece às determinações da LAI, mas já eram seguidos também por leis anteriores que exigiam sua publicação, tais como a Lei das Licitações, Lei do Pregão Eletrônico e a Lei da Transparência Fiscal.

Por outro lado, itens mais específicos da LAI, tais como classificação das informações sigilosas, cópias de contratos, disponibilização de 
relatórios em formatos de planilha ou texto e estruturação da informação, obtiveram descumprimento acima de $90 \%$. Esse comportamento pode ser compreendido como uma dificuldade que as autarquias federais podem estar encontrando em produzir informações mais específicas, que necessitam de maior esforço em produzi-las, pois não se trata apenas de cumprir uma Lei; mais do que isso, a LAI provoca uma mudança paradigmática nas Organizações Públicas e na forma de geri-la, transformando o amplo acesso às informações como regra e o sigilo a exceção, sendo o Open Government Partnership um movimento internacional bastante recente sobre o assunto e do qual o Brasil é signatário, que impulsiona a participação popular na Administração Pública.

Nesse sentido, percebeu-se que as autarquias, por estarem sujeitas a leis mais rígidas com relação à transparência de sua gestão, estavam aparentemente mais preparadas para atender requisitos mais abrangentes da LAI, já que eram contemplados em legislação anterior, mas que podem estar encontrando dificuldades em cumprir com itens mais específicos da referida Lei. Ressalta-se, como limitação deste estudo, que os resultados encontrados foram verificados com base na amostra selecionada, na metodologia utilizada e no período investigado.

Desse modo, para a realização de estudos futuros, recomenda-se replicar o instrumento desta pesquisa aos Estados e Municípios, assim como verificações futuras da evolução da conformidade das autarquias pesquisadas, para fins de comparação da observância da LAI. Ainda como recomendação, também se faz pertinente orientar as autarquias, órgãos e entidades federais a realizar pesquisas de satisfação junto aos usuários, a fim de avaliar a facilidade de uso das ferramentas disponibilizadas para acesso à informação e identificar possíveis necessidades de melhoria.

\section{Referências}

ACESSO À INFORMAÇÃO. Acesso à informação no mundo: governo aberto. Disponível em: <http://www.acessoainformacao.gov.br/acessoainformacaogov/acessoinformacao-mundo/governo-aberto.asp>. Acesso em: 9 dez. 2012a.

ACESSO À INFORMAÇÃO. Acesso à informação no Brasil. Disponível em: <http://www.acessoainformacao.gov.br/acessoainformacaogov/acessoinformacao-brasil/index.asp >. Acesso em: 9 dez. 2012b.

ANGÉLICO, F. Lei de acesso à informação pública e seus possíveis desdobramentos à accountability democrática no Brasil. 2012. 133 f. Dissertação (Mestrado em Administração Pública e Governo) - Escola de Administração de Empresas de São Paulo, Fundação Getúlio Vargas, São Paulo, 2012.

ARAÚJO, W. G. F.; LAIA, M. M. Governança eletrônica e gestão da informação em portais de governo: uma análise da reestruturação do Portal Minas. In: ENCONTRO NACIONAL DA ASSOCIAÇÃO NACIONAL DE 
PÓS-GRADUAÇÃO E PESQUISA EM ADMINISTRAÇÃO, 2004. Anais... Curitiba, 2004. p.1-16.

BARBOSA, A. F. Governo eletrônico: dimensões da avaliação de desempenho na perspectiva do cidadão. 2008. 248f. Tese (Doutorado em Administração de Empresas) - Escola de Administração de Empresas de São Paulo, Fundação Getúlio Vargas, São Paulo, 2008.

BRASIL. Constituição da República Federativa do Brasil, de 8 de outubro de 1988. Diário Oficial [da] República Federativa do Brasil, Brasília, DF, 5 out. $1988 . \quad$ Disponível em: <http://www.planalto.gov.br/ccivil_03/constituicao/constituicao.htm>. Acesso em: 2 jan. 2013.

BRASIL. Lei n. 12.527, de 18 de novembro de 2011. Regula o acesso a informações previsto no inciso XXXIII do art. 5o, no inciso II do $\S 30$ do art. 37 e no $\S 20$ do art. 216 da Constituição Federal; altera a Lei no 8.112, de 11 de dezembro de 1990; revoga a Lei no 11.111 , de 5 de maio de 2005, e dispositivos da Lei no 8.159, de 8 de janeiro de 1991; e dá outras providências. Diário Oficial [da] República Federativa do Brasil, Brasília, DF, 18 nov. 2011. Disponível em: <http://www.planalto.gov.br/ccivil_03/_ato2011-

2014/2011/lei/l12527.htm>. Acesso em: 2 jan. de 2013.

BRASIL. Lei n. 8.666, de 21 de junho de 1993. Regulamenta o art. 37, inciso XXI, da Constituição Federal, institui normas para licitações e contratos da Administração Pública e dá outras providências. Diário Oficial [da] República Federativa do Brasil, Brasília, DF, 22 jun. 1993. Disponível em: <http://www.planalto.gov.br/ccivil_03/leis/L8666cons.htm>. Acesso em: 4 jan. 2013.

BRASIL. Lei n. 10.520, de 17 de Julho de 2002. Institui, no âmbito da União, Estados, Distrito Federal e Municípios, nos termos do art. 37, inciso XXI, da Constituição Federal, modalidade de licitação denominada pregão, para aquisição de bens e serviços comuns, e dá outras providências. Diário Oficial [da] República Federativa do Brasil, Brasília, DF, 18 jul. 2002. Disponível em: <http://www.planalto.gov.br/ccivil_03/leis/2002/L10520.htm>. Acesso em: 4 jan. 2013.

BRASIL. Lei Complementar n. 131, de 27 de Maio de 2009. Acrescenta dispositivos à Lei Complementar no 101, de 4 de maio de 2000, que estabelece normas de finanças públicas voltadas para a responsabilidade na gestão fiscal e dá outras providências, a fim de determinar a disponibilização, em tempo real, de informações pormenorizadas sobre a execução orçamentária e financeira da União, dos Estados, do Distrito Federal e dos Municípios. Diário Oficial [da] República Federativa do Brasil, Brasília, DF, 28 mai. 2009. Disponível em: < http://www.planalto.gov.br/ccivil_03/Leis/LCP/Lcp131.htm>. Acesso em: 4 jan. 2013. 
BRASIL. Lei Complementar n. 101, de 04 de Maio de 2000. Estabelece normas de finanças públicas voltadas para a responsabilidade na gestão fiscal e dá outras providências. Diário Oficial [da] República Federativa do Brasil, Brasília, DF, 5 mai. 2000. Disponível em: <http://www.planalto.gov.br/ccivil_03/leis/LCP/Lcp101.htm>. Acesso em: 4 jan. de 2013.

CONTROLADORIA GERAL DA UNIÃO. Acesso à informação pública: uma introdução à lei no 12.527, de 18 de novembro de 2011. Brasília:CGU, 2011. Cartilha.

CONTROLADORIA GERAL DA UNIÃO. Acesso à informação e controle social das políticas pública. Brasília: ANDI, Artigo 19, 2009. Disponível em: $<$ http://www.cgu.gov.br/acessoainformacao/materiais-interesse/Acesso-a-informacao-econtrole-social-das-politicas-publicas.pdf >. Acesso em: 9 jan 2013.

DINIZ, E. H. et al. O governo eletrônico no Brasil: perspectiva histórica a partir de um modelo estruturado de análise. Revista de Administração Pública, v. 43, n. 1, p. 23-48, jan.-fev. 2009. Disponível em: < http://www.scielo.br/pdf/rap/v43n1/a03v43n1.pdf >. Acesso em: 9 jan 2013.

EVANS, D.; YEN D. C. E-Government: evolving relationship of citizens and Government, domestic, and international development. Government Information Quarterly, v. 23, p. 207-235, 2006.

GRUMAN, M. Lei de acesso à informação: notas e um breve exemplo. Revista Debates, v. 6, n. 3, p. 97-108, set./dez. 2012.

JAEGER, P. T.; THOMPSON, K.M. Social information behavior and the democratic process: information poverty, normative behavior, and electronic government in the United States. Library \& Information Science Research, v. 26, p. 94-107, 2004.

LAIA, M. M. et al. Eletronic government policies in Brazil: context, ICT management and outcomes. Revista de Administração de Empresas, v. 51, n. 1, p. 43-57, jan.-fev. 2011. Disponível em: < http://www.scielo.br/pdf/rae/v51n1/05.pdf >. Acesso em: 13 jan. 2013.

LEMOS, A. Cidade, tecnologias e interfaces: análise de interfaces de portais governamentais brasileiros. Uma proposta metodológica. Revista Fronteiras. Estudos Mediáticos, v. VI, n. 2, p. 117-136, 2004.

MEIJER, A. J.; CURTIN, D.; HILLEBRANDT, M. Open Government: connecting vision and voice. International Review of Administrative Sciences, v. 78, n. 1, p. 10-29, 2012.

MEDEIROS, P. H. R; GUIMARÃES, T. A. A relação entre governo eletrônico e governança eletrônica no governo federal brasileiro. Cadernos EBAPE.BR, v. 3, n. 4, p. 1-18, 2005.

MELLO, G. R.; SLOMSKI, V. Índice de governança eletrônica dos estados brasileiros (2009) no âmbito do poder executivo. Revista de Gestão da Tecnologia e Sistemas de Informação (Journal of Information Systems and Tecnology Management), v. 7, n. 2, p. 369-402, 2010. 
MICHENER, M. G. The Surrender of Secrecy? Explaining the Strength of Transparency and Access to Information Laws. In: APSA 2009 TORONTO MEETING PAPER. Proceedings... Toronto, Canada, 2009. Working Paper no 1449170. Disponível em: <http://ssrn.com/abstract $=1449170>$. Acesso em: 8 jan. 2013.

OPEN GOVERNMENT PARTNERSHIP - OGP. Práticas de governo aberto. Disponível em: < http://www.cgu.gov.br >. Acesso em: 9 jan. 2013.

PINHO, J. A. G. Investigando portais de governo eletrônico de estados no Brasil: muita tecnologia, pouca democracia. Revista de Administração Pública, v. 42, n. 3, p. 471-493, 2008.

REZENDE, D. A.; FREY, K. Administração estratégica e governança eletrônica na gestão urbana. Revista Eletrônica de Gestão de Negócios, v. 1, n. 1, p. 51-59, 2005.

WELCH, E. W., HINNANT. C. C.; MOON, M. J. Linking Citizen Satisfaction with E-Government and Trust in Government. Journal of Public Administration Research and Theory, v. 15, n. 3, p. 371-391, 2005. 